\title{
Psychological gender, self-esteem, body-esteem, and the use of wellness treatments in women with excessive body weight
}

\author{
Monika Bąk-Sosnowska, Dominika Shala
}

Department of Psychology, Chair of Social Sciences and Humanities, School of Health Sciences in Katowice, Medical University of Silesia in Katowice, Poland

\begin{abstract}
Introduction: Psychological gender is a set of features culturally assigned for a man or woman. It has an impact on self-esteem and life activity. The aim of this study was to evaluate the association between psychological gender, and overall level of self-esteem, body-esteem, and use of wellness treatments in women with excess body weight.
\end{abstract}

Material and methods: The study included 120 adult women with excessive body weight. The mean age was $36.9 \pm 12.30$ years, average body weight was $81.99 \pm 9.50 \mathrm{~kg}$, and mean BMI was $29.88 \pm 2.78 \mathrm{~kg} / \mathrm{m}^{2}$. Half of the respondents at least once in the past year used wellness treatments (group A), and the other half never did (group B). We used: the Sex-Roles Inventory (IPP), Self-Esteem Scale (SES), Body-Esteem Scale (BES), silhouette test (FRS), and our own questionnaire.

Results: Group A and B were homogeneous due to age, body mass, and body mass index ( $p>0.001$ ). The groups did not differ $(p=0.06)$ in IPP, although an unspecified type of psychological gender dominated in group A (50\%) and feminine type was the most popular in group B (40\%). The groups did not differ in terms of SES $(p=0.14)$, both dominated by low self-esteem. In all categories of BES (sexual attractiveness, weight concern, physical condition), low results dominated in both groups. There were no significant differences between the groups except the category of physical condition, in which group B achieved higher results $(p<0.05)$. In FRS the actual silhouette was estimated as bigger than the ideal silhouette in group $\mathrm{A}(p<0.001)$ and $\mathrm{B}(p<0.001)$. There were no significant differences between the groups in that area $(p=0.4099)$. There was no correlation between the results of IPP, SES, and BES.

Conclusions: There is no relationship between the use of wellness treatments by women with excessive body weight and their psychological gender, self-esteem, sexual attractiveness, and weight concern. However, women enjoying wellness differ in terms of physical condition from women who do not benefit from this type of treatment.

Key words: psychological gender, self-esteem, body-esteem, wellness treatment, excessive body weight.

\section{Introduction}

Psychological gender is a set of psychological features culturally assigned for a woman or man. This is formed from childhood as a result of the process of socialisation and assimilation of stereotypical definition of femininity and masculinity. The presence of feminine or masculine psychological features in the individual is not related to his/her biological sex.
According to the theory of gender schemes by Sandra Lipstiz Bem [1], masculinity is identified with characteristics like: expansiveness, domination, independence, competition, decisiveness, confidence, drive for success, good physical condition, sense of humour, and tendency to experiment in sex. Femininity is related to: sensitivity, sensibility, delicacy, modesty, naivety, caring, willingness to make sacrifices, engaging in the affairs of others, attention to appearance, and aesthetics. Bem singled out four

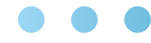

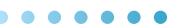


main configurations of psychological features related to psychological gender, which results in four types of psychological gender:

- sex registered people - people whose psychological gender corresponds to their physical sex (feminine women and masculine men); realised behaviour in these people consistent with social expectations regarding to femininity or masculinity,

- androgynous people - people who have both masculine and feminine traits, regardless of their biological sex; these people can realise behaviour defined as masculine or feminine depending on the requirements of the situation; that type of psychological gender is considered as the most adaptive and beneficial for mental health,

- undefined people - individuals who have low identification with either feminine or masculine characteristics, regardless of their biological sex; these persons do not reveal features in their behaviours which are described as typically masculine or feminine,

- cross-sex typed people - individuals whose psychological gender is the opposite of their biological sex (feminine men and masculine women); these persons manifest behaviours inconsistent with social expectations regarding femininity and masculinity.

Standards created by culture apply not only to the features and behaviour considered as typically masculine and feminine, but they also focused on appearance. Overall body image assessment is in a large part due to the comparison with the body image promoted by mass media [2]. Patterns of physical attractiveness are prohibitive especially in relation to women. They relate primarily to making young appearance and thinness. Especially the thin body is considered as a symbol of self-control, self-care, and life success [3]. Women who are not able to answer the social pressure regarding appearance are exposed to low self-, which often affects not only the body, but also other areas of functioning. As a result of self-dissatisfaction, the risk of depression, eating disorders, and difficulty in interpersonal relationships increases [4-6]. Research shows that obese women have lower quality of life than thin woman or obese men [7].

In order to minimise the negative consequences of low self-esteem, individuals make efforts to temporarily improve physical and psychological well-being. These actions may include using treatments which improve the condition and appearance of the body. Wellness means the impact of the human body for the prevention of overwork, maintaining or improving physical fitness, optimising physiological processes of rest, returning to full physical efficiency and psychological motivation [8]. In common sense, it refers to any relaxation and beauty treatment. Wellness treatments include, among others: water baths, low or high temperature influence, electro- stimulation, body treatments using natural mineral-organic materials, and massages.

In this paper, it is assumed that overweight women benefit from wellness treatments not only for bioregeneration but also to improve their self-esteem and body satisfaction. It has also been assumed that women with feminine type of psychological gender are more likely to benefit from wellness treatments because special attention to the appearance is attributed to this type of gender category. The aim of this study was to evaluate the relationship between psychological gender, self-esteem, body-esteem, and the use of wellness in women with excessive body weight.

\section{Material and methods}

\section{Participants}

The study involved 146 people. Inclusion criteria for the study group contained: female sex, age over 18 years, body mass index greater than 25 , experience of at least one-time use of wellness treatments (group A) or never did (group B), response to all questions in the questionnaires, and agreement to study participation. Finally, 120 people were included in the study. Other people completed questionnaires in incomplete form.

\section{Methods}

All participants were weighed using electronic scales with a maximum lifting capacity of $180 \mathrm{~kg}$, they were also measured using the steel tape measure of length $2.5 \mathrm{~m}$. On this basis, the body mass index (BMI) was calculated.

The diagnostic survey method was used to collect the remaining research material. The following research tools were used:

- The Inventory of Psychological Gender (IPP) by A. Kuczyńska is a tool used to assess the psychological gender of an individual. It consists of 35 items, 15 of which create a femininity scale, 15 a masculinity scale, and five others are neutral positions. The participant is asked to mark at each position a number that determines how much this term is appropriate for him/her. The results for each subscale are summed up, and on this basis the severity of the following four categories of psychological gender are set: femininity, masculinity, androgenism, and sexually undefined.

- The Self-Esteem Scale by M. Rosenberg (SES), in the Polish adaptation by I. Dzwonkowska, K. Lachowicz-Tabaczek, M. Łaguna. It is a one-dimensional tool for evaluating the level of general self-esteem. It consists of 10 diagnostic statements. The participant is asked to indicate on a four-level scale how much he/she agrees with each of these statements. According to the instructions, the score is reversed for some statements, and then all points are added. In order to 
Table 1. Selected anthropometric parameters in study groups

\begin{tabular}{|l|l|c|c|}
\hline Basic statistics & Group A & Group B \\
\hline \multirow{4}{*}{ Age (years) } & Mean value & 36.50 & 37.30 \\
\cline { 2 - 4 } & Standard deviation & 11.34 & 13.28 \\
\cline { 2 - 4 } & Minimum & 19.00 & 18.00 \\
\cline { 2 - 4 } & Maximum & 64.00 & 67.00 \\
\hline \multirow{4}{*}{$\begin{array}{l}\text { Body mass } \\
\text { (kilograms) }\end{array}$} & Mean value & 81.20 & 82.78 \\
\cline { 2 - 4 } & Standard deviation & 9.39 & 9.63 \\
\cline { 2 - 4 } & Minimum & 65.00 & 64.00 \\
\cline { 2 - 4 } & Maximum & 103.00 & 99.00 \\
\hline \multirow{4}{*}{ BMI (kg/m 2$)$} & Mean value & 29.74 & 30.02 \\
\cline { 2 - 4 } & Standard deviation & 2.82 & 2.76 \\
\cline { 2 - 4 } & Minimum & 25.08 & 25.78 \\
\cline { 2 - 4 } & Maximum & 37.83 & 37.46 \\
\hline
\end{tabular}

compare the obtained result with a general result for the Polish population, it is transformed into a 10-point sten scale, where a sten of 1-3 signifies low intensity of the tested variable, sten] 4-6 average, and sten 7-10 high intensity of the tested variable.

- The Body-Esteem Scale (BES) by S. Franzoi and S. Shields, in the Polish adaptation by M. Lipowska and M. Lipowski. It contains 35 definitions for parts and functions of the human body. The participant is asked to mark in each term a number which reflects how he/she perceives the part or function of his/her own body. Answers give results in three categories, which for women include: sexual attractiveness, weight concern, and physical condition. The scale has standards for the Polish population, so the results of each category are transformed into a sten scale.

- The Figure Rating Scale (FRS) is a picture test. It consists of drawings of nine female silhouettes, varying in body weight from very slim to obese. The participant is asked to indicate a character that resembles the current and ideal of his or her own body. The test can be used to determine the discrepancy between the current and the ideal body image.

- Own questionnaire containing 10 questions. The first question was related to the experience in using wellness treatments. Group B participants did not continue to answer the remaining questions, and group A responded to the type of treatment being performed, the reasons for use, and the benefits they received.

\section{Research procedure}

The study was carried out in the wellness surgery and a neighbouring hairdressing salon. Participation in the study was offered to clients who subscribed to the service on randomly selected days of the week from the begin- ning of January to the end of March 2015. After consenting to participate in the study, anthropometric measurements were made, and then the participants responded to the questionnaires. Answers were provided during the surgery/salon stay, individually, anonymously, and with no time limit. The respondents did not receive remuneration or any type of rebate for participation in the study.

Statistical analysis of the data was carried out in Statistica 10 software from StatSoft Polska. In all analyses, the level of statistical significance was assumed at $\alpha<0.05$. Due to the fact that not all the tested variables had a normal distribution, non-parametric tests were used: $\chi^{2}, U$ Mann Whitney, Wilcoxon.

\section{Results}

The mean age in whole study group was $36.9 \pm 12.30$ years, mean body weight was $81.99 \pm 9.50 \mathrm{~kg}$, mean BMI was $29.88 \pm 2.78 \mathrm{~kg} / \mathrm{m}^{2}$. The detailed characteristics of groups A and B are shown below (Table 1).

Groups A and B were homogeneous in terms of age, body weight, and BMI $(p>0.05)$.

The most popular wellness treatments performed in group A included: relaxation massage (46.70\%), body treatments with peeling and mask $(43.30 \%)$, and anti-cellulite massage with Chinese bubble (41.7\%). Other treatments used $43.30 \%$ included: sauna, Jacuzzi, mud, warm and cold baths, cryostimulation, laser, and solarium.

As a primary reason for using wellness treatments, participants reported: improvement of body appearance $(66.7 \%)$, relaxation $(60 \%)$, and increased self-esteem (56.7\%). Almost half of the respondents $(41.7 \%)$ said that they always feel better after using the wellness and 38.3\% said that it always improved their mood.

In group A, sexually undefined type of psychological gender dominated, and in group B it was feminine type (Figure 1). In terms of IPP results the groups did not differ significantly $(p=0.06)$.

In the SES questionnaire, the low scores were dominant in both groups. The details are shown in Figure 2. The groups did not differ significantly $(p=0.14)$.

In all categories of BES (sexual attractiveness, weight concern, physical condition), in groups A and B, low scores dominated (Figure 3 ). There were no significant differences between the groups except for physical conditions $(p<0.05)$.

In the silhouette test (FRS) the current figure was judged to be slimmer than the ideal figure in both group A $(p<0.001)$ and B $(p<0.001)$. The average results of both estimates are presented in Figure 4 . There were no significant differences between the groups in terms of the current silhouette $(p=0.99)$ and the ideal one $(p=0.49)$.

No correlation was found between the results of IPP, SES, BES, and FRS in any of the studied groups. 


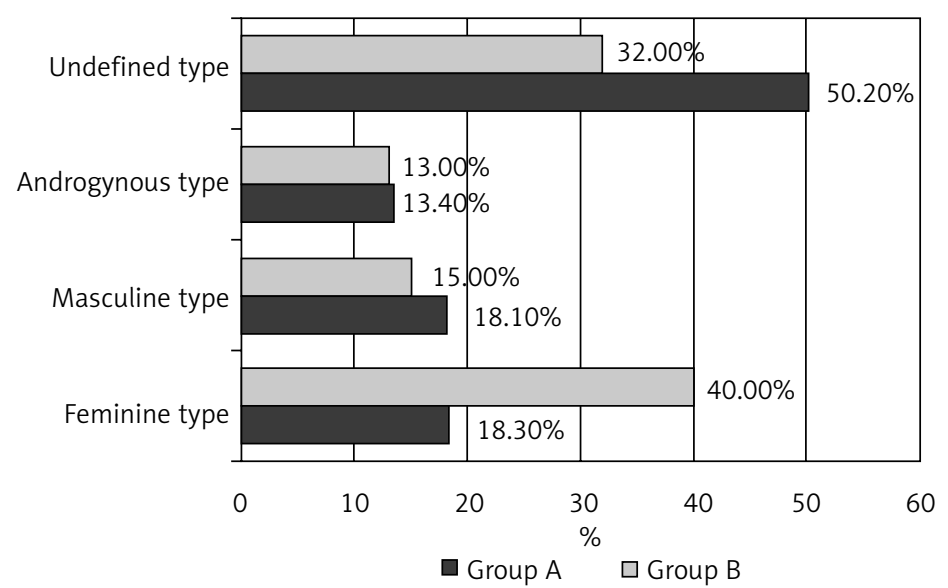

Figure 1. Psychological gender (IPP) in study groups

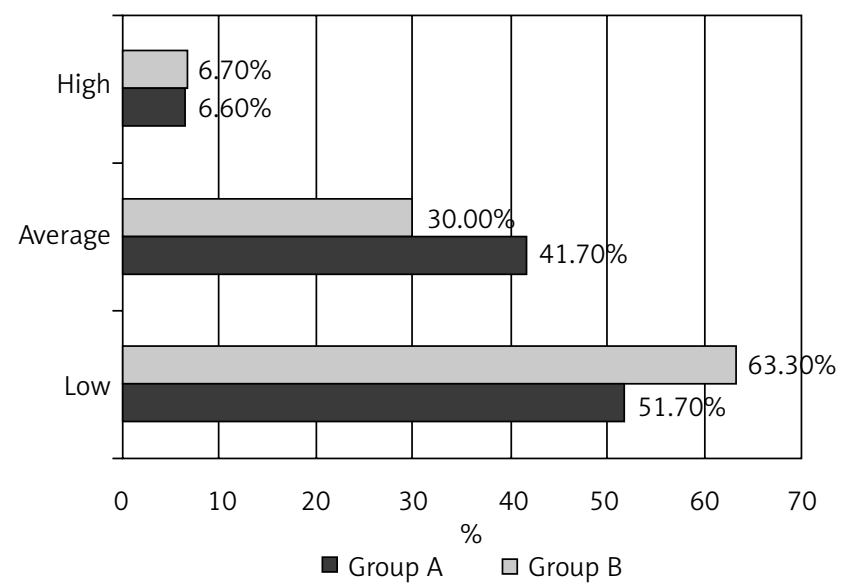

Figure 2. Self-esteem (SES) in study groups

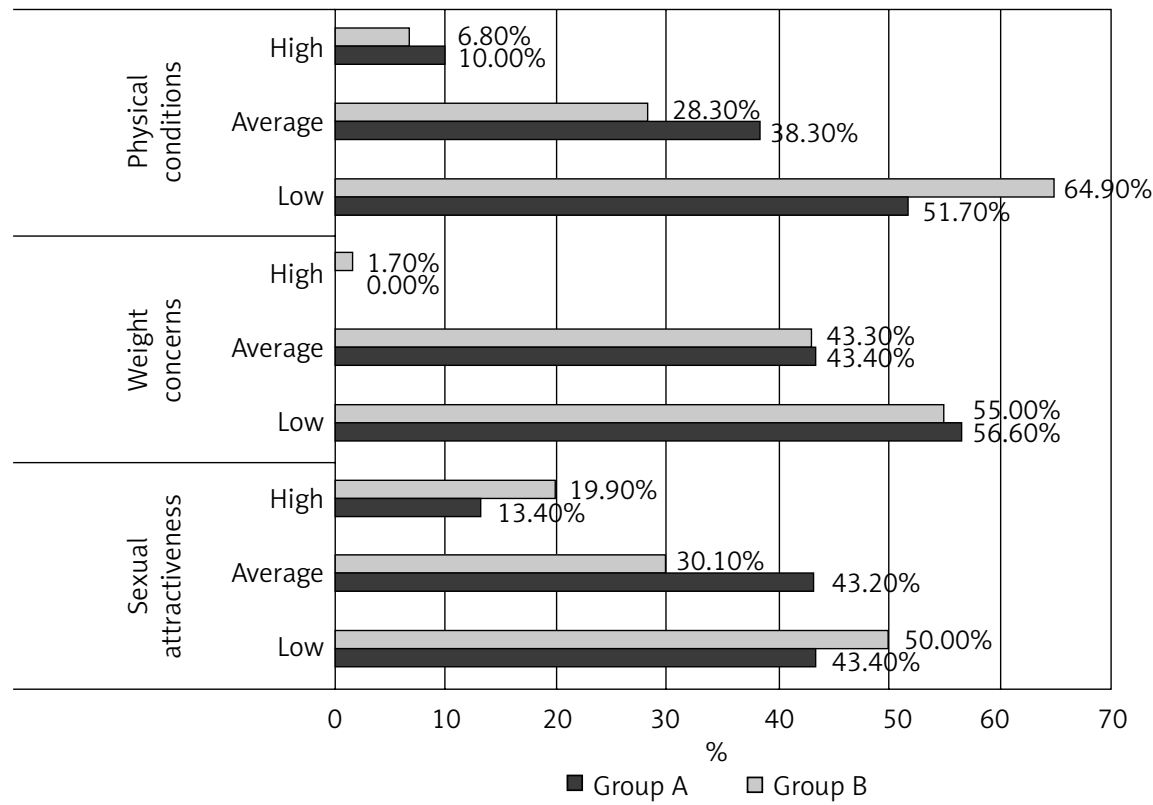

Figure 3. Body-esteem (BES) in study groups 


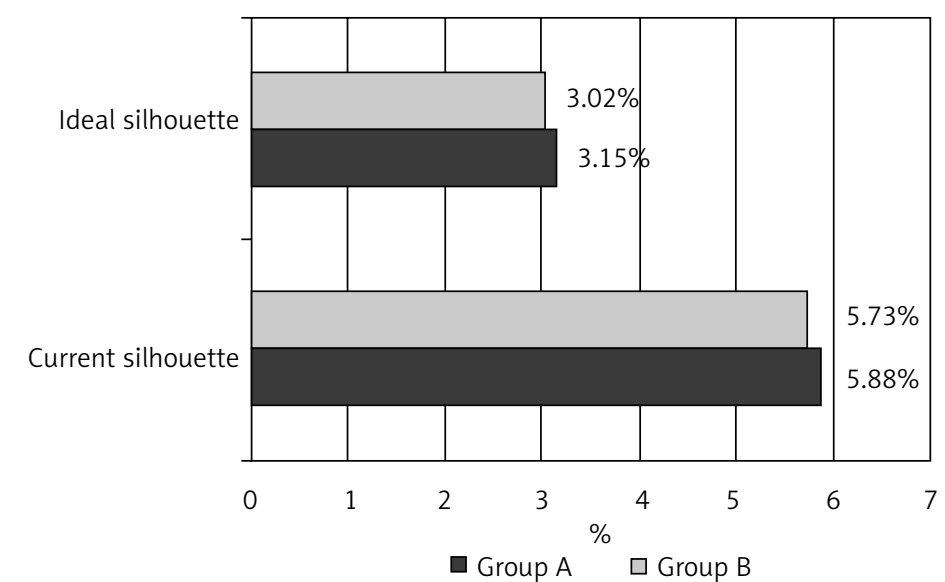

Figure 4. Silhouette-esteem (FRS) in study groups

\section{Discussion}

The analysis of responses to our own questionnaire confirmed that one of the most important reasons for the use of wellness treatments by women with excessive body weight is their desire to improve their appearance and self-esteem. The reasons declared by the participants were adequate to their age (average 37 years) and the fact that they used the treatment ambulatorily and occasionally. Those who chose health spa treatments were usually older and their primary goal was to improve health and reduce pain. In addition, regarding the ambulatory wellness place, a particular emphasis was placed on the decor and pleasant atmosphere of the visit, which is meant to encourage relaxation.

Although the participants declared that they always had better physical and mental well-being after using wellness treatments, the results of the other questionnaires did not confirm that their overall self-esteem and body-esteem differed significantly from women who did not receive such treatment. Perhaps the reason is the nature of the services provided, because massage, bath, or body mask leave no visible changes in appearance, as opposed to aesthetic medicine. Gawron [9] found that women who underwent, for example, wrinkle correction, lip enlargement, nose correction, or facial contour had significantly higher scores in the BES questionnaire and improved well-being compared to the control group. Also, a study by Hibler et al. [10] confirmed that after improving facial defects, the quality of life measured in terms of emotional functioning and evaluation of appearance improved.

In our study, the only difference in body-esteem between women who benefited and those who did not benefit from wellness treatments was the assessment of their physical condition. It was higher in the study group benefiting from the wellness. This result can be attributed to the nature of the regeneration centers, whose primary purpose is to improve both mental and physical condition [11]. It should be noted that the BES questionnaire does not diagnose the actual physical condition of the respondents, but only their subjective feeling about this aspect of the functioning of the body.

Regardless of whether they used or did not use a wellness treatment, the largest group of participants was characterised by low self-esteem and low body-esteem, in terms of sexual attractiveness, weight concern, and physical condition. Sexual attractiveness is related to the perception of those parts of the body whose appearance cannot be changed by physical exercise, but by modelling them with, for example, make-up. On the contrary, weight concern is about parts of the body that can be altered by exercise or diet. Physical condition refers to the evaluation of parameters such as endurance, strength, and agility. The results are consistent with other authors pointing to the stigmatizing effects of overweight and obesity, especially in the female population [12]. Women with excessive body weight not only have a lower self-esteem, but are also vulnerable to social discrimination, which may be related to intimate, social, and occupational situations [13-15].

The participants in both groups perceived their current silhouette as bigger than the silhouette they would like to have. The assessment of the size of their body did not correlate with the use or not of wellness treatment, although it may seem that such treatments as body massage can affect the subjective perception of one's body. Dissatisfaction with body mass and body composition is not unique to overweight or obese women. Also, women with normal weight and even underweight want to be slimmer than they are at present. This phenomenon does not occur in male populations, where greater body mass is associated positively, with strength and dominance [16].

The results of the questionnaire surveying psychological gender deviate from the initial research assumptions. It was assumed that the interest in wellness treatments 
would be more characteristic for women with female gender types. However, it turned out that these types of women predominate in the group not using body treatments. In the group using wellness treatments the most popular was undefined psychological gender. According to Bem [17], undefined gender is characterised by lower self-esteem compared to those of the other types. Although such a dependence was not observed in our study, the desire to improve self-esteem and mental well-being was declared as the main cause of the use of wellness treatments.

The relationship between the specific psychological gender and female-specific activity was not confirmed by Pacut's study [18]. Using the IPP questionnaire, he examined athletes practicing gymnastics and synchronised swimming. He showed female psychological gender in $41 \%$ of the respondents, which did not differ significantly from the control group. In turn, a study of female soccer players showed that $70 \%$ of athletes were characterized by androgenic type psychological gender [19].

An open question remains about the relationship of a particular psychological gender with female body weight. Among all the respondents, the group was dominated by undefined type of psychological gender (41\%), followed by female type (29\%). This is not consistent with the results of a cross-sectional study of Orzeszek [20], which evaluated the psychological gender of women aged 22-31 years. In this study, $47 \%$ of the participants were female type, and only $9 \%$ were sexually undefined. A Pubmed database search covering the years 2017-2000 did not reveal any reports regarding the estimation of the psychological gender of the obese.

Although the dimension of psychological gender is considered to be essentially unchanging in adult life, it can be hypothesised that significant somatic changes may be a disturbed factor in this regard. Perhaps this includes, among others, excessive body weight, which is related to activation of psychological defence mechanisms. To confirm this hypothesis, we would require a separate study. Overeating may in some cases be considered a self-destructive mechanism leading ultimately to death due to complications of obesity. In one study involving self-destructive behaviour, it was shown that the predominant psychological gender was undetermined type [21].

\section{Conclusions}

There is no relationship between the use of wellness treatment by women with excessive body weight and their type of psychological gender, general self-esteem, sense of sexual attractiveness, and weight concern. Women who use wellness treatments differ from women who do not use these types of treatments in terms of their physical condition.

\section{Disclosure}

Authors report no conflict of interest.

\section{References}

1. Bem SL. Gender schema theory: A cognitive account of sex typing. Psychol Rev 1981; 88: 354-364.

2. Mirucka B, Sakson-Obada O. Ja cielesne. Od normy do zaburzeń. GWP, Sopot 2013.

3. Engeln-Maddox R. Buying a Beauty Standard or Dreaming of a New Life? Expectations Associated with Media Ideals. Psychol Women Quart 2006; 30: 258-266.

4. Sides-Moore L, Tochkov K. The thinner is the better? Competitiveness, depression and body image among college student women. Coll Stud I 2011; 45: 439-448.

5. Daniali S, Azadbakht L, Mostafavi F. Relationship between body satisfaction with self-esteem and unhealthy body weight management. J Educ Health Promot 2013; 2: 29.

6. Forsén Mantilla E, Bergsten K, Birgegård A. Self-image and eating disorder symptoms in normal and clinical adolescents. Eat Behav 2014; 15: 125-131.

7. Saraç F, Parýldar S, Duman E, et al. Quality of life for obese women and men in Turkey. Prev Chronic Dis 2007; 4: A50.

8. Wojtanowska J, Niewęgłowska-Wilk M, Wilk T. Motywy korzystania i poziom zadowolenia klientów Uzdrowiska Swoszowice. Estetol Med Kosmetol 2012; 2: 21-23.

9. Gawron D. Wpływ zabiegów upiększających na ocenę własnego wyglądu i nastrój u kobiet w wieku średnim. Psychologia Jakości Życia 2013; 12: 97-110.

10. Hibler BP, Schwitzer J, Rossi AM. Assessing Improvement of Facial Appearance and Quality of Life after Minimally-Invasive Cosmetic Dermatology Procedures Using the FACE-Q Scales. J Drugs Dermatol 2016; 15: 62-67.

11. Alejziak B. Usługi SPA \& Wellness jako element zdrowego stylu życia. Turystyka i Rekreacja 2014; 11: 72-81.

12. Ratcliffe D, Ellison N. Obesity and internalized weight stigma: a formulation model for an emerging psychological problem. Behav Cogn Psychother 2015; 43: 239-252.

13. Obara-Gołębiowska M. Employment discrimination against obese women in obesity clinic's patients perspective. Rocz Panstw Zakl Hig 2016; 67: 147-153.

14. Lee JA, Pausé CJ. Stigma in Practice: Barriers to Health for Fat Women. Front Psychol 2016; 7: 2063.

15. Boyes AD, Latner JD. Weight stigma in existing romantic relationships. J Sex Marital Ther 2009; 35: 282-293.

16. Grossbard JR, Neighbors C, Larimer ME. Perceived norms for thinness and muscularity among college students: what do men and women really want? Eat Behav 2011; 12: 192-199.

17. Bem SL. Sex role adaptability: One consequence of psychological androgyny. J Person Soc Psychol 1975; 31: 634-643.

18. Pacut A. Poczucie tożsamości płciowej kobiet a uprawiana przez nie dyscyplina sportu. Sport Wyczynowy 2006; 3-4: 495-496.

19. Soroka A, Bergier J. Sense of gender identity in women practicing football with consideration of the formation. Pol J Sport Tourism 2011; 18: 45-58.

20. Orzeszek A. Sexual Identity in Women at the Threshold of Their Adulthood. Annals of Pedagogies 2013; 5: 115-140.

21. Tsirigotis K, Gruszczyński W, Tsirigotis-Maniecka M. Indirect selfdestructiveness and psychological gender. Psychiatr Pol 2014; 48: 759-771. 